\title{
METHODOLOGIES USED IN PROJECT MANAGEMENT
}

Adrian UNGUREANU, Lecturer Ph.D. Anca UNGUREANU, Assistant Professor Ph.D. anca2063@yahoo.com

\begin{abstract}
Undoubtedly, a methodology properly defined and strictly followed for project management provides a firm guarantee that the work will be done on time, in budget and according to specifications. A project management methodology in simple terms is a "must-have" to avoid failure and reduce risks, because is one of the critical success factors, such basic skills of the management team. This is the simple way to guide the team through the design and execution phases, processes and tasks throughout the life cycle of project management. Project management methodology is a strictly defined combination on practices regarding logic, methods and processes that determine how best to plan, develop and control a project along the continuous process of its implementation and successful completion. In project management there are various approaches and methods that can be used in different types of project management. All types of project methodologies can be divided into traditional and modern approaches.
\end{abstract}

Keywords: project management methodology, planning, control process

JEL Classification: $\mathrm{M}_{10}, \mathrm{M}_{21}$

\section{State of knowledge}

In the early 1900s, Henry Gantt, a famous engineer in industry, marked the beginning of current project management practices, which were then called methodologies, by developing the famous Gantt charts or bar chart [Kliem, Ludin, Robertson, 1997]. Initially the diagram had a simple role to indicate the number of days that a task needs to be completed. Later, progress in terms of production planning and control has led to improvements in project management practices. In the late 1950s, two important technical plans have emerged, PERT (Program Evaluation and Review Technique) and critical path method - CPM [Kliem, Ludin, Robertson, 1997]. These techniques allow project management to evolve and develop more and more elaborated plans, both for public sector and private sector projects.

The term "project management methodology" was first defined in the early 1960s, when various business organizations have begun to seek effective ways that could simplify the realization of benefits out of businesses and work organization in a structured and unique entity (which was later called "Project"). Communication and collaboration were key criteria for establishing productive working relationships between teams and departments within one and the same organization. Since then, the term has been changed and amended several times, 
new definitions have been created, new features and new functions have been added. Today it is considered that a project management methodology is a set of principles and general rules to manage a specific project that has a well definite beginning and an end.

\section{Introduction}

Project management methodology is a strictly defined combination on practices regarding logic, methods and processes that determine how best to plan, develop and control a project along the continuous process of its implementation and successful completion.

It is a scientifically proven, systematic and disciplined approach of the project regarding the implementation and completion. The aim of the project management methodology is to allow the control of the whole process of management through effective decision-making and problem solving, while ensuring the success of specific processes, approaches, techniques, methods and technologies. Usually, a methodology provides a skeleton framework to describe each step in depth, so that a project manager will know what to do in order to provide and implement activities according to the schedule, the budget and the specifications [Kerzner, 2004, p. 18]. Regarding the given definition, a project management methodology chosen properly paves the way to obtaining the following achievements:

- the needs of the interested parties are defined;

- a common 'language' is established and understood by the team, for a communication as accurate as possible;

- cost estimates are complete, accurate and reliable;

- each task is done using a common methodological approach;

- most conflicts are spotted and addressed earlier;

- expected results are produced and delivered;

- lessons are learned and solutions are implemented quickly.

Figure no. 1. The basic layout of Project Management methodology

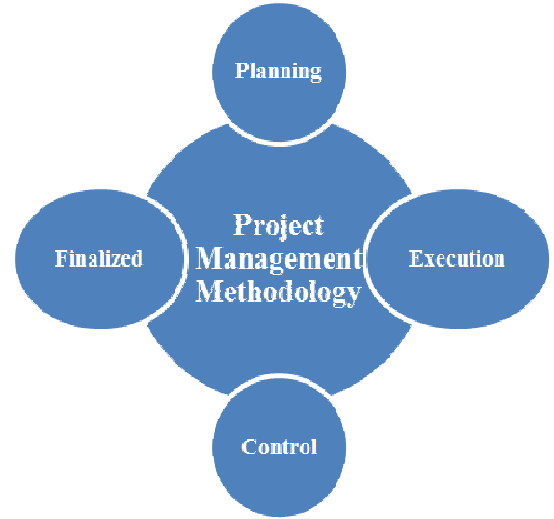

Source: Personal processing 
Project management provides the planning framework, realises and provides projects of any kind, size, nature and type. Framework-project management focuses on achieving the desired changes in accordance with a chosen methodological approach. In fact, change is the basic aspect which would be managed. Framework-project management identifies and defines how to best manage change. And the methodology serves as the "way" to systematically achieve changes in terms of time, cost and quality. Project management means the description and performance of the necessary activities to meet the specific objectives that lead to making changes. For example, writing a book is a kind of project where the goal is to write a book. This can be achieved through a series of successive activities, including defining the subject, collecting supporting materials, creating a draft of the book, typing, proofreading and others. So, in terms of project management, the author should define and then complete all the activities necessary in order to write a book (which means it makes a change).

Framework-project management is a structured collection of all relevant knowledge, on how to make a difference in terms of methodology. It does not describe an exact algorithm of the management of the specific project, but provides a broad overview of the variety of methods, rules, processes and standards. In this respect, the methodology of project management can be defined as a special level of framework-project management.

A simplified example of how a project methodology can be presented in the hierarchical management structure can be seen below:

Figure no. 2. The hierarchical structure of the project methodology

Project Management Framework

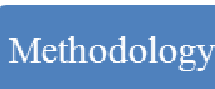

The stages of the project life cycle

Groups of processes

Tasks and activities

Source: Personal processing

\section{Types of project management methodologies}

In project management there are various approaches and methods that can be used in managing different types of projects. All types of project methodologies can be divided into traditional and modern approaches. 


\section{The traditional approach}

A traditional approach involves a series of sequential steps in the process of project management. It is a process that takes place step by step to design, develop and deliver a product or service. This requires the achievement of the succession in the implementation process and provides the planning benefits based on Milestone and team building. In the IT and software development field, this type of methodology is called "Waterfall" - a working stage after another in linear sequence.

The following steps are included in traditional project management methodology:

- initiation (tender specifications requirements);

- planning and design;

- implementation (construction and coding);

- control and integration;

- validation (testing and debugging);

- closing (installation and maintenance).

\section{Modern approaches}

Modern methodologies do not focus on linear processes, but they provide an alternative approach to project management. Some of the methods are best for IT and software development, while others may be implemented in production, to improve the processes in various other fields, in production technology etc. Modern approaches to project management use different models of the management process. The most popular project management methodologies are [Meredith, Mantel, 2009, p. 384]:

- PMBOK Guide. Although it is a guide to "Project Management Body of Knowledge", it is not a "pure" project management methodology, but many people consider it as a methodological approach for planning, execution, control and completion of various projects. PMBOK Guide can be defined as a broad inventory of best practices and ideas on project planning and implementation. Project Management Institute (PMI) was founded in 1969, initially to identify common management practices in projects across the industry. The first edition of the PMBOK was published in 1987. This was the result of work undertaken since the early 80 's by the Project Management Institute (PMI), while also being developed a Code of Ethics and Guidelines for accreditation of training centres and certification of individuals. Later, a second version of the PMBOK was published in 1996 and then in 2000, based on comments received from members. PMBOK was recognized as a standard by the American National Standards Institute (ANSI) in 1998, and later received accreditation from the Institute of Electrical and Electronics Engineers (IEEE) as well. In 2004, PMBOK Guide - Third Edition was published with major changes from previous editions in PDF version, with major improvements in the document, additions to processes, terms and domains of program and portfolio. The fourth edition was published in 2009. The latest edition in English of the PMBOK Guide is the fifth edition, which was issued in 2013 [PMBOK 2013, p. 153]. 
PMBOK Guide is process based, which means that it describes the work accomplished by processes. This approach is consistent with other management standards such as ISO 9000 and CMMI Software Engineering Institute. Processes overlap and interact throughout a project or during its various stages. The processes are described in terms of:

- entries (documents, plans, drawings, etc.);

- tools and techniques (mechanisms applied to inputs);

- outputs (documents, plans, drawings, etc.).

Guide to the Project Management Body of Knowledge - Fifth Edition provides guidelines for the management of individual projects and defines concepts related to project management. The guide also describes the life cycle of project management and related processes and project life cycle.

The guide recognizes 47 processes that are grouped into five major groups based on process and ten knowledge areas that are typical for most projects, most of the time.

- PRINCE2 Methodology Projects in Controlled Environments, 2nd Edition regards the project management as a series of logical processes and procedures to create a framework for implementing well controlled projects. This methodology provides a process-based approach that can be applied to all types of projects. Being originally developed in the UK as a standard of project management dedicated to IT, today the method is widely used in many countries around the world, as it offers a series of standardized processes and procedures for controlled and efficient planning and implementing many types of projects in safety conditions. PRINCE2 is the second version of the previously called PRINCE methodology, which was developed and first made public in 1989 by CCTA [Turley, 2010, p. 81] (Central Computer and Telecommunications Agency), a government support agency in the UK. The first edition of the methodology has been regarded as a simple set of strict standards for project management in IT. Later, the PRINCE method has proven high efficacy in the management of various projects in different fields, than IT. Since then, more and more companies began to use it in order to plan, implement and control all types of efforts within projects.

The second edition of the methodology - PRINCE2 was launched in 1996 as a generic project management methodology. Since that time, PRINCE2 started to become increasingly popular among many organizations in the UK involved in different types of projects, becoming today a methodology that has acquired the status of planning and project management standard in the UK. Gradually, this methodology has spread beyond the UK in over 50 other countries. Today, PRINCE2 is characterized as a methodology of rapidly growing international interest, while incorporating the existing requirements and experiences of countless of users around the world.

As a definition, PRINCE2 represents a systematic project management methodology, which consists of a series of high-level processes for planning, implementation, monitoring and reviewing of a project by creating a wellstructured and clearly described environment. This is an international standard used on a global scale, for projects planning and implementation, which provides a 
flexible and adaptable approach to suit the general requirements of the project and to address the needs of the initial business idea. The goal of the PRINCE2 approach is to develop a project management framework in well-controlled environments. For those who use it, PRINCE2 is actually applying the best practice that has been developed and tested since the late 1980s by multiple organizations. This project management methodology incorporates the experience of many years of best practices in projects planning and implementation and offers a complete and logical set of processes to ensure that all important aspects (such as business problems, quality requirements, time, human resources) of a project are treated properly.

- CPM - Critical Path Method explores the most important or critical tasks in a project by defining the possible sequences of activity and estimating the longest duration of each sequence. This method helps estimate the time it will take to complete the work and what tasks will form the scope of application.

- Lean. Lean project management methodology aims to maximize the value given to the customer and minimize the waste of resources. This methodology enables organizations to create greater value for their customers with fewer resources. The concerned approach achieves perfection through customer satisfaction and by generating value in the implementation process of an optimized process flow that eliminates the waste of products, services, transport, stocks etc.

- Six Sigma method was originally developed by Motorola to improve the production processes by eliminating defects (defined as "non-conformity of a product or service regarding its specifications"). Today, Six Sigma is one of the most popular and reliable project management methodologies, even worldwide. The essential approach of this methodology, in order to ensure the accuracy and speed of implementation of a process, resorts to the elimination or minimization of losses.

- CCPM. Critical Chain Project Management is the methodology that consists in the way of planning, implementing and reviewing the different types of work in different environments, from a single project and multiple projects. This methodology uses the Restrictions Management theory (TOC) and the concept of "buffers" to establish improved activity durations and manage tasks and resource dependent activities.

- SCRUM. It is a method part of the Agile methodology, involving teams in producing a software product within 30 days "sprint" and "monthly SCRUM sessions". In a SCRUM led project, deliverables are divided into intervals of 30 days. This example of methodology is specific and applicable especially for collaborative teams, $100 \%$ dedicated, and not strongly constrained by time and budget for materials. The name comes from the Agile method, a group of methodologies based on common principles of software development which later took the name "agile software development". Methodologies like that tackle a different style for the project management and focuses on: continuous inspection of the implementation process; team and the importance of teamwork, continuously encouraged team leader; maximum responsibility and self-organization, leading the 
development of a software product in a very short time, superior quality and in direct correlation, including the entire process, customer requirements and objectives. Most Agile methodologies propose teamwork and establish on-going collaboration and adaptability throughout the project life cycle and development iterated, this signifying the production of one or more products feature parts with a well-defined role in a project, following that whole iteration to render the complex product, the final [Kalermo, Rissanen, 2002, p. 121]. In 2001, between 11 and 13 February, in the resort Lodge, Wasatch Mountains, Utah [Agile Manifesto 2014] Agile Manifesto was born after a meeting attended by 17 specialists in management and software, the meeting was focused on how to make the production of software as simple as possible, as quickly and centred around the individual.

\section{References}

Kalermo J.; Rissanen J. (2002), Agile software development in theory and practice, Software Business Program Master's thesis, University of Jyvaskyla, http://www.cs.jyu.fi/sb/Publications/KalermoRissanen_MastersThesis_060802.pdf, last accessed on 15 sept. 2014.

Kerzner H. (2004), Advanced Project Management, Best practices on implementation, Kliem R.L.; Ludin I.S.; Robertson K.L. (1997), Project Management Methodology, A practical guide for the next millennium, Marcel Dekker, New York, USA.

Martin R.C. (2003), Agile Software Development: Principles, Patterns, and Practices, Prentice Hall PTR upper Saddle River, NJ, USA.

Meredith J.R.; Mantel Jr. S.J. (2009), Project management, A managerial approach, Eight edition, John Wiley\&Sons, Inc., NJ, USA.

Turley F. (2010), PRINCE@ Foundation Training Manual, Foundation Q\&A Workbook.

*** A Guide to the Project Management Body of Knowledge (PMBOK), Fifth edition, Project Management Institute, Pennsylvania, USA, 2013.

***Manifestul Agile, http://agilemanifesto.org/history.html, last accessed on 15 sept. 2014. 
